\title{
MANAGEMENT OF SHAQEEQA (MIGRAINE) BY HIJAMA BISH SHART (WET CUPPING) AND NUTOOL THERAPY - A CASE STUDY
}

\author{
Mohammad Tausif ${ }^{1}$, Abdul Tawwab Ansari ${ }^{2}$ \\ Prof. Anisur Rahman ${ }^{3}$ and Mohammad Rais ${ }^{2}$
}

Assistant professor, Dept. of Ilaj bit Tadbeer, State Unani Medical College Prayagraj, Uttar Pradesh P.G Scholars, Dept. of Ilaj bit Tadbeer, State Unani Medical College Prayagraj, Uttar Pradesh Professor, Dept. of Ilaj bit Tadbeer, State Unani Medical College Prayagraj, Uttar Pradesh

\section{Review Paper}

Received: 20.09.2021

Revised: 30.09.2021

Accepted: 10.10.2021

\section{ABSTRACT}

Unani system of medicine or Greeko-Arab medicine, founded by Hippocrates is based on the concept of balance and equilibrium of natural body humors (Akhlat) i.e. (Blood, Phlegm, Bile and Black bile). Any imbalance in quality and quantity of these humors leads to various diseases where as restoration of this equilirium maintains health. In present era man is subjected to various challenges and stressful situations every day in there life as a result of which pain in the head or headache is very common. Among various types of headache, Shaqeeqa (migraine) is the most important one. In Unani system of medicine Shaqeeqa (migraine) is treated by a number of single or compound drugs and through various regimens of Ilaj bit tadbeer like Hijama bish shart (wet cupping), Fasd (venesection), Dalk (massage), Nutool therapy etc. In this case study Hijama bish shart (wet cupping), applied on the Al-kahil region, total 3 sittings of wet cupping were done on every $5^{\text {th }}$ day after that 5 sittings of nutool therapy were done on every $3^{\text {rd }}$ day. Considerable improvement both in disease process and in quality of life was achieved.

No. of Pages: 3

References: 13

Keywords: Shaqeeqa, Ilaj bit tadbeer, Hijama bish shart, Nutool.

\section{INTRODUCTION}

Shaqeeqa is derived from an Arabic word "shaq" meaning apart or aside. ${ }^{[1]}$ This is also known as sudaenisfi or Adha sisi. ${ }^{[1,2,3,4]}$ Shaqeeqa (migraine) is a desease caused by imbalance of Akhlat (humors) in the body. ${ }^{[1,2]}$ Shaqeeqa is described since ancient time. Many eminent unani physicians like Jalinoos (Galen), Ibne Sina (Avicenna) and Razi described its etiology, prevention and treatment. It has been described in the Ebers Papyrus, dated around1500 BC as "sickness of the half of the head." According to Jalinoos this pain occurs in weakest part of the brain. According to
Ibne Sina this pain occur either in meninges of the brain or out side of the brain in the muscles of temporal region. Its cause involves morbid vapours and humoral imbalance. ${ }^{[5]}$ Alteration in Asbabe sitta zarooriya leads to various diseases of which Shaqeeqa is the one. Some Unani physicians described that the pain is due to bukharat (gaseous) or rutubat e ghaleeza (viscid matters) which accumulate in the weaker part of the head. ${ }^{[6,7]}$ According to involvement of khilt (humour), shaqeeqa is classified in to four types $\mathrm{v}$ i $\mathrm{z}$. shaqeeqae damvi (due to imtela or congestion of blood), shaqeeqae balghami (due to imtela or congestion of phlegm),

*Corresponding author: mohdtausif328@gmail.com 
shaqeeqae safravi (due to imtela or congestion of bile) and shaqeeqae saudavi (due to imtela or congestion of black bile). These four types are classified in to two broad categories according to temperament of morbid matters v i z. (1) Shaqeeqae har (migraine due to hot temperament of morbid matters which includes Dam and Safra) and (2) Shaqeeqae barid (migraine due to cold temperament of morbid matters which includes Balgham and Sauda). ${ }^{[1,2]} \mathrm{A}$ classical migraine starts with prodrome of malaise, lethargy, vague yawning, giddiness followed by the aura of a focal neurological event and then as ever throbbing unilateral headache associated with photophobia nausea and vomiting. ${ }^{[8,9]}$ It may last for few hours to several days. The Global Burden of Disease Study 2010, ranked migraine as the third most prevalent disorder in the world. The International Headache Society (IHS) has classified migraine in to several types, among them two are common v i z. (1) Migraine without aura (earlier known as common migraine), (2) Migraine with aura. The IHS has given criteria for the diagnosis of common migraine is recurrent attack of headache lasting 4-72 hours, characterized by headache is unilateral location, pulsating quality, moderate or severe intensity, aggravation by routine physical activity and association with nausea and/or photophobia and phonophobia. ${ }^{[10]}$ Earlier, it was regarded that vascular phenomenon play main role to produce headache in migraine but recent studies have shown that migraine occurs due to disturbance in brain where both nerves and neurotransmitters such as nitric oxide (NO), serotonin (5-HT) and calcitonin gene related peptide (CGRP) are also involved in pathophysiology of migraine. ${ }^{[10,11,12]}$ In conventional system of medicine, migraine is treated by nonspecific drugs like NSAID'S, and specific drugs such as ergot derivatives, 5HT receptor agonist, beta blockers, calcium channel blockers, anticonvulsant drugs etc. ${ }^{[13]}$ Definitely these drugs provides relief on short term basis, but long term use of these drugs causes dependence, drug withdrawal symptoms and so many side effects. In Unani system of medicine management of Shaqeeqa is based on the evacuation of morbid matter followed by Ta'deel-e-mizaj (restoration of normal temperament). For evacuation of morbid matter several methods are used e.g Munzij- mushil therapy (Concoction and purgation), Hijama bish shart (Wet cupping), Fasd (Venesection), Idrar (Diuresis) etc. among them Hijama bish shart (Wet cupping) is most commonly used. In this case study we have used Hijama bish shart (Wet cupping) for the purpose of evacuation of morbid matter and Nutool therapy for the purpose of Ta'deel-e-mizaj (restoration of normal temperament).

\section{MATERIALSAND METHODS}

A 25 year old male patient visited in the OPD of Ilaj bit tadbeer in State Unani Medical College, Prayagraj with the chief complaint of headache for more than 4 years. According to the patient his pain was episodic in nature, and was aggravated during empty stomach, traveling, exposure to sunlight and in inadequate sleep condition, the episode of pain occurs almost every week which persists for several hours, during the episode patient also develop some degree of nausea \& vomiting. Patient daily routine was restricted and was unable to do their personal work; patient also had concentration and sleeping difficulty. The patient had no history of any metabolic disease, hypertension and tuberculosis. On general examination, his vitals are within normal limit and no abnormality was detected through systemic examination. X-ray PNS report shows no any abnormality. Based on the above findings this episodic pain in head was clinically diagnosed as Shaqeeqa (Migraine).

Before starting the procedure patient underwent through examination necessary for starting the wet cupping like CBC, BT, CT, HIV, HBsAg and VDRL. Before starting the cupping the target area Al-kahil region (Interscapular region)was cleaned with the spirit and then cup was applied without scarification with two large sized cups for 10-12 minutes. The benefit of dry cupping (cupping without scarification) is that it increases the blood circulation of that area which helps in easily evacuation of the morbid matter. After that cup was removed and 14-15 superficial incision were made on the same area and the same cup was applied again on that part. When the cup was applied after incision, the blood is coming out and starts to collect within the cup. After some time the bleeding is stops and the blood inside the cup is coagulated, then cup was removed gently. Finally the area is cleaned and dressed. Total 3 sitting were done on $0^{\text {th }}, 5^{\text {th }}$, and $10^{\text {th }}$ day. After completion of the 3 sittings of wet cupping, from the next day Nutool therapy was started with Roghane Gul which cantains Gule surkh (Rosa damascena) and Roghane kunjad (Sesamum indicum). Total 5 sittings of Nutool therapy were done on every $3^{\text {rd }}$ day. The patient was advised to lie in supine position on the specially designed table for the Nutool therapy and his eyes were covered by cotton pad to prevent entering of drug in to the eyes. The irrigation with Roghane Gul (500 ml) was done from one and half feet height over the forehead of the patient.

\section{RESULT}

Before starting the study the patient's severity of pain due to headaches was 7 on VAS scale (on 0-10 scale, 0 being no pain and 10 is the most severe it can be) two days after second sitting of wet cupping the patient have one episode which is of shorter duration and on VAS scale the severity of pain is reduced to 3. During the Nutool therapy patient have no any episode of headache and the patient's daily activities and concentration on work are improved. After the completion of treatment protocol, the patient returned for follow up after 1 month. The patient 
reported that he has no any episode of headache and he is continuing their study without the fear of migraine.

\section{DISCUSSION}

Migraine is one of the commonest causes of the headache although it is not life threatening but it reduces the quality of life and over all productivity of the patient. As it is known that there is no cure for migraine and the pharmacological treatment options are very much limited, hence now a day the non-pharmacological treatment like Cupping (Hijama therapy), Massage (Dalk), Acupuncture, Yoga etc. becomes popular. These therapies not only alleviate the pain but it acts on the root cause of the disease and improves the over allwell being of the patients. The trends of Hijama therapy are increasing day to day but it is not a new therapy it is used since antiquity. It removes the harmful substances and toxins which are in Unani medicine called as Fasidmadda from the body to promote healing. On the other hand Nutool therapy is also a very popular mode of treatment in Unani system of medicine which is usefull in the treatment of certain diseases e.g. Headache, Insomnia, Melancholia, Migraine, cystitis and arthritis etc. Nutool therapy acts by altering the temperament of diseased organ or by normalization of morbid temperament and by providing the strength (Taqwiyate Aza). When the diseased organ get their normal temperament back which is the root cause of the disease its Quwwate mudafiat (Defence mechanism) improves which restores the health. The result of this study suggest that Hijama bish shart (Wet cupping) followed by Nutool therapy may be beneficial for Migraine (Shaqeeqa), however the finding can not be generalized, so further studies are recommended on large number of patients to established the effect of Hijama bish shart (Wet cupping) and Nutool therapy and also the long term follow up should be done to know the long term effect.

\section{CONCLUSION}

Patient case report reveals that applying Hijama bish shart (wet cupping) followed by Nutool therapy is quite effective in the management of Shaqeeqa (Migraine). Hence it is recommended that further randomized clinical trials should be done to validate their efficacy in the management of Shaqeeqa (Migraine).

\section{REFERENCES}

1. Kabeeruddin A.H. Sharah e Asbab. Idarakitabul Shifa. New Delhi. 2009; Vol1: 39-44.
2. Khan A. Akseer eAzam (Urdu translationby Kabeeruddin AH). New Delhi. Idara Kitabul Shifa; 2011; 77.

3. Tabri M. Moalajat Buqratiya (Urdu Translation). New Delhi, CCRUM. 1995;1: 284,290.

4. Jilani G. MakhzanulIlaj, New Delhi; Darya Ganj; Idara Kitabul Shifa, 2005: 22-23.

5. Ibne Sina. Al Qanoon fit Tib. (Urdu Translation by Kintoori GH)Vol 3, Part 1. New Delhi: Idara Kitabus Shifa, YNM, 530,531.

6. Azam R., Jabeen A., Jilani S., Jahangiri U. Shaqiqa (Migraine): A historic perspective in Unani system of medicine. International Journal of Institutional Pharmacy and Life Sciences. 2017; 7(6):123-129.

7. Sarfraz MD, Siddiqui MA, Arshid IW, Nasimul $\mathbf{H}$. Concept of Migraine and its management in Unani system of medicine. Am. J. PharmTech Res. 2013;3(6):212-219

8. Munjal Y.P., Sharma S.K., Kamanth S.A., Agarwal A.K., et al. API Text book of Medicine. $9^{\text {th }}$ Ed.Vol 1:2012: 12-15.

9. Golwalla AF, Golwalla SA. Medicine for Students.22 ${ }^{\text {nd }}$ Ed. Mumbai; 2008: 499-504.

10. Pearce J.M. Historical aspects of migraine. Journal of neurology, neurosurgery, and psychiatry. 1986 Oct; 49(10) : 1097.

11. Neuropsychiatric Dis. Treat. "Prophylaxis of migraine: general principles and patient acceptance” Dec2008; 4(6) :1155-1167.

12. Saxena P.R., P. felt-Hansen P.: “Triptans, 5-HT1B/1D receptor agonist in the acute treatment of migraines”. The Headache Lippincott Williams and Wilkins, Philadelphia Olesen J., Goadsby PJ, Ramadan N.N., T. felt Hansen P., Welch KMA, 2006; (3):469-503.

13. Tripathi K.D. Essentials of Medical Pharmacology. $5^{\text {th }}$ Ed. New Delhi. Jaypee Brothers Medical Publisher (P) Ltd. 2003, 153-154. 